\title{
Technical and economic analysis of parameters of urban distribution electric networks $10 \mathrm{kV}$
}

\author{
A D Taslimov', $S$ A Keshuov ${ }^{2}$, Najimatdinov $R K^{3}, K h$ Aminov $^{1}, A$ A Yuldashev ${ }^{3}$, \\ ${ }^{1}$ Tashkent State Technical University named by Islam Karimov, Tashkent, Uzbekistan \\ ${ }^{2}$ Kazakh National Agrarian University, Almaty, Kazakhstan \\ ${ }^{3}$ Karakalpak State University
}

\begin{abstract}
In the article, using the criterion analysis method, the analysis of the stability of total costs, the sensitivity of parameters to changes in the initial data (to the analysis of the influence of errors in the initial data) is carried out, and recommendations are given on the use of the obtained parameters for $10 \mathrm{kV}$ distribution electrical networks.
\end{abstract}

Keywords. Optimization, unification, optimal parameters, stability, sensitivity, similarity criterion.

\section{Introduction}

Solving the problem of choosing the parameters of electrical distribution networks (DET) requires the use of methods of mathematical and geometric programming. This method is the method of criterion analysis or programming [1-3], which makes it possible to solve a complex of problems of choosing parameters. An important advantage of the criterion analysis method is that some tasks of quantitative analysis (for example, the stability of the technical and economic function to parameters, the sensitivity of optimal solutions to the initial data) are solved without knowing the numerical values of the initial data [7-11].

Consider the total costs of $10 \mathrm{kV}$ DET for one power source (PS), which, taking into account the total capital costs, operating costs and electricity losses, are determined by the expression [4-5]:

$Z_{C}=Z_{C(1)} \sigma^{-0.5} S_{T(i)}^{-0.25} S_{P S}^{0.75} M_{C}^{0.5}+Z_{C(2)} \sigma^{-0.5} S_{T(i)}^{0.31} S_{P S}^{0.19} M_{C}^{1.06} F_{H, C}+$ $Z_{C(3)} \sigma^{-0.5} S_{T(i)}^{-0.88} S_{P S}^{1.38} M_{C}^{-0.13} F_{H, C} N_{F C}^{-1}+Z_{C(4)} \sigma^{-0.5} S_{T(i)}^{0.04} S_{P S}^{2.46} M_{C}^{-1.21} F_{H, C}^{-1} N_{F C}^{0.3}$

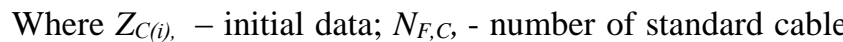
cross-sections; $F_{H, C}$, - cross-sections of the head sections of cable lines $10 \mathrm{kV}, \mathrm{mm}^{2} ; M_{C}$, - the number of lines outgoing from one PS; $S_{P S}$ - power PS, mVA; $S_{T(i)}$ - installed capacity of transformers, $\mathrm{kVA} ; \sigma$ - electrical load density, referred to as PS tires, $\mathrm{mVA} / \mathrm{km}^{2}$.

On the basis of (1), using the criterion analysis method, the economic values of the DET parameters corresponding to the minimum total costs are determined. The calculation results and their analysis are given in [6].

It should be pointed out that the results obtained in [5] are intermediate, since they were obtained without taking into account the stability and the zone of equal efficiency of total costs. The study of the stability of the total costs of $10 \mathrm{kV}$ DET in the area of its minimum involves an analysis of the applicability of discrete standard values of economic parameters in the area of equal efficiency of total costs and creates the prerequisites for further unification of these parameters [12-19].

To study economic sustainability based on (1), we write down the general criterion equation for a $10 \mathrm{kV}$ network in the following form:

$$
Z_{i}^{*}=\pi_{1 e} M_{i}^{* 0,5}+\pi_{2 e} M_{i}^{* 1,06} F_{2, i}^{*}+\pi_{3 e} M_{i}^{*-0,13} F_{2, i}^{*}{ }^{*} N_{F, i}^{*-1}+\pi_{4 e} M_{i}^{*-1,21} F_{2, i}^{*-1} N_{F, i}^{* 0,3},
$$

Where $\left\langle{ }^{*}\right\rangle-$ means that all parameters are expressed in relative units from their economic values; $\pi_{1 \mathrm{e}}, \pi_{2 \mathrm{e}}, \pi_{3 \mathrm{e}}, \pi_{4 \mathrm{e}}-$ similarity criteria for economic options. Similarity criteria in matrix form are determined by the formula (2):

$$
\begin{aligned}
& \pi_{E}=\left(\alpha^{T}\right)^{-1} \cdot \beta \text {, }
\end{aligned}
$$

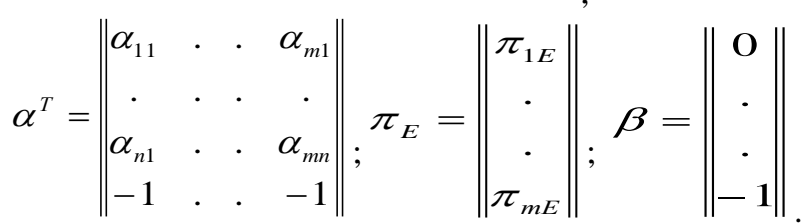

Here $\alpha^{T}$-parameter exponent matrix; $\pi_{\mathrm{E}}-$ columnar matrix of similarity criteria; $m$ - number of components of total costs; $\mathrm{n}$ - number of parameters.

For model (1), we compose the transposed matrix from the exponents of the parameters $\alpha^{T}$ and find the inverse matrix

$$
\left(\alpha^{T}\right)^{-1}: \quad \alpha^{T}=\left\|\begin{array}{cccc}
0 & 0 & -1 & 0,3 \\
0 & 1 & 1 & -1 \\
0,5 & 1,06 & -0,13 & -1,21 \\
-1 & -1 & -1 & -1
\end{array}\right\|
$$




$$
\left(\alpha^{T}\right)^{-1}=\left\|\begin{array}{|cccc}
-1,579 & -1,743 & 1,327 & -0,336 \\
1,553 & 1,26 & -0,464 & -0,232 \\
-0,763 & 0,111 & -0,199 & -0,1 \\
0,79 & 0,372 & -0,664 & -0,332
\end{array}\right\| .
$$

In this case, the economic values of the similarity criteria in matrix form are:

$\left\|\begin{array}{l}\pi_{1 E} \\ \pi_{2 E} \\ \pi_{3 E} \\ \pi_{4 E}\end{array}\right\|=\left\|\begin{array}{cccc}-1,579 & -1,743 & 1,327 & -0,336 \\ 1,553 & 1,26 & -0,464 & -0,232 \\ -0,763 & 0,111 & -0,199 & -0,1 \\ 0,79 & 0,372 & -0,664 & -0,332\end{array}\right\| \cdot\left\|\begin{array}{c}0 \\ 0 \\ 0 \\ -1\end{array}\right\|=\| \begin{gathered}0,336 \\ 0,232 \\ 0,1 \\ 0,332\end{gathered}$

Thus, the economic values of the similarity criteria are:

$$
\begin{aligned}
& \pi_{1 E}=0,336 ; \quad \pi_{2 E}=0,232 ; \\
& \pi_{3 E}=0,1 ; \quad \pi_{4 E}=0,332 .
\end{aligned}
$$

Taking into account the values of the similarity criteria, the criterion equation takes the form:

$$
Z_{*}=0,336 M^{M} i
$$

From equation (3) we obtain expressions that are directly used to study the economic sustainability of total costs:

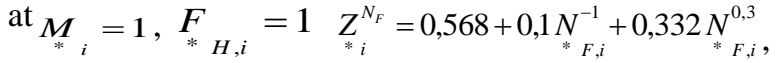

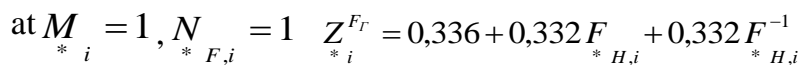

$$
\begin{aligned}
& \text { at } F_{*_{\Gamma, i}}=1,{ }_{* F, i}=1 \quad Z_{*_{i}}^{M}=0,336{ }_{*_{i}}^{M_{i}}+0,232{ }_{*_{i}}^{1,06}+0,1 M_{*_{i}}^{-0,13}+0,332{ }_{*_{i}}^{-1,21}
\end{aligned}
$$

The analysis of the economic sustainability of total costs to changes in parameters is carried out according to the dependences in Fig. 1 constructed according to criterion equations (4) - (6).

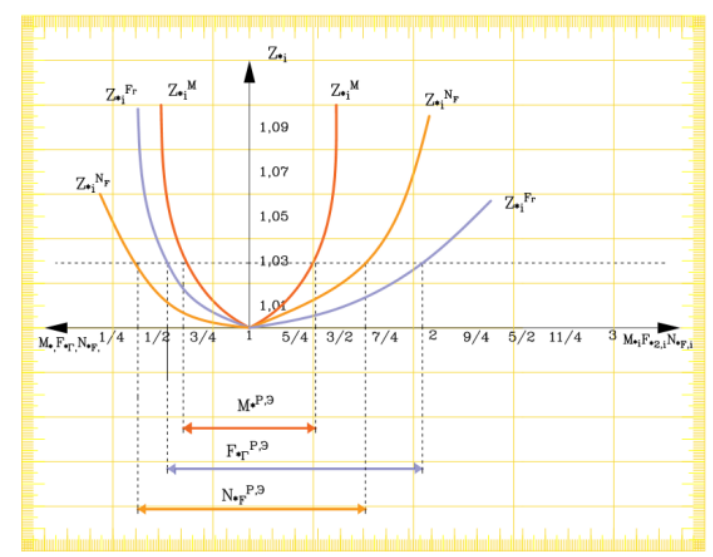

Fig.1. Investigation of the stability of the function of total costs to deviations of parameters from their economic values

Dependencies Fig. 1 allow to determine the degree of economic stability of the total costs for $10 \mathrm{kV}$ DET to changes in individual parameters.

Fig. 1 it follows that the total costs are most resistant to changes in the parameters $N_{F, i}$ and $F_{, H, i}$ and to the least extent to changes in the parameter $M_{i}$. In general, the parameters $N_{F, i}$ and $F_{, H, i}$ have a significant area of equal efficiency; for example, when

$Z_{*}=1,05: N_{*_{F, i}}^{D . E}=0,37-1,6, \quad F_{*_{H, i}}=0,45-1.9$.

Thus, a significant equally economical zone of total costs for the parameters $N_{F, i}$ and $F_{, H, i}$ on the one hand, creates the preconditions for the unification of cable cross-sections, on the other hand, it does not allow to unambiguously select these parameters - the number and values of standard crosssections of $10 \mathrm{kV}$ DET cables. In this case, additional criteria are used for the final selection of these parameters [20-26].

The obtained economic values of the parameters depend both on the initial data and on the completeness and accuracy of the total costs. When forming the total costs of $10 \mathrm{kV} \mathrm{DET}$ as a function of the number of cable cross-sections used, a number of assumptions and approximations were made, which affected the values of the generalized coefficients $Z_{C(i)}$ . In addition, the influence of the initial data error on the parameters of the $10 \mathrm{kV}$ DET needs to be clarified for practical purposes. Therefore, it is necessary to investigate the influence of possible changes in the initial data (generalized coefficients) on the values of the parameters, that is, the sensitivity of the economic parameters $N_{F, i}, F_{2, i}$ and $M_{i}$. From (5) we get:

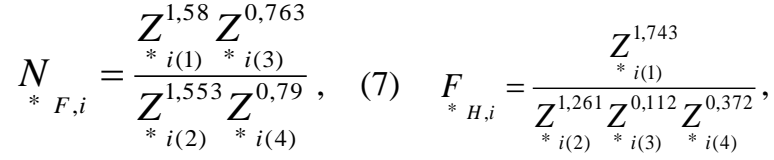

$$
\begin{aligned}
& M_{* i}=\frac{Z^{0,465} Z_{i(2)}^{0,2} *_{i(3)}^{0,6(4)}}{Z^{1,317}},(9)
\end{aligned}
$$

Where $\mathrm{i}=\mathrm{n}, \mathrm{c}$.

Expressions (7)-(9) show how the possible ranges of variation of the error of generalized constants (initial data) affect the economic values of the parameters. By $(7) \div(9)$ graphs of sensitivity were constructed (Fig. 2a, b, c).

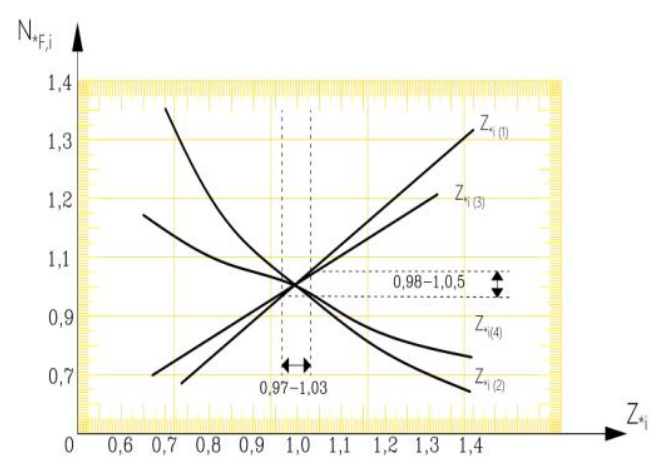

a) 


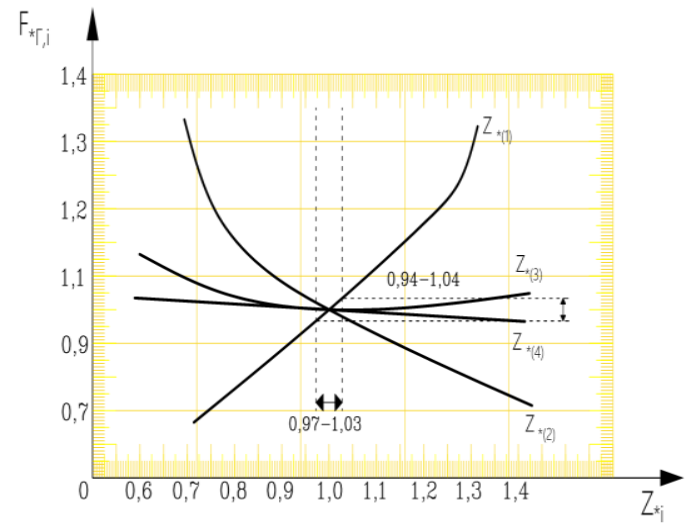

b)

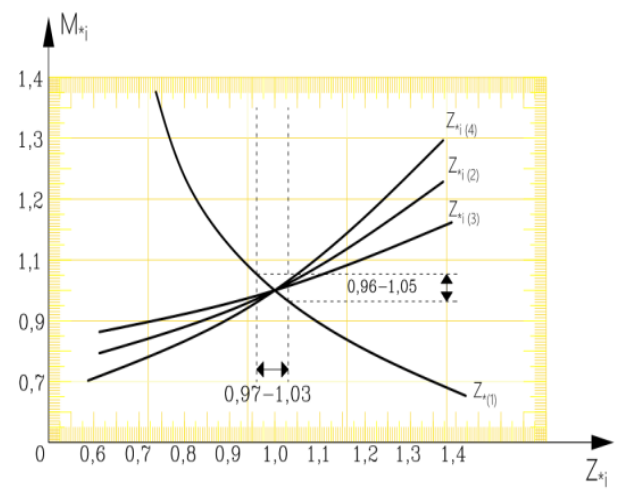

c)

Fig. 2. Sensitivity of the number of used cable cross-sections (a), the cross-section of the head sections of the lines (b) and the number of lines outgoing from the PS (c) to changes in the initial data.3

As can be seen from Fig. 2c the number of outgoing lines $10 \mathrm{kV} \mathrm{M}_{\mathrm{C}}$ (from PS) is most sensitive to a change in the generalized constants $\mathrm{Z}_{\mathrm{C}(1)}$, determined by the constant part of the unit cost of $10 \mathrm{kV}$ cable lines $\mathrm{M}_{\mathrm{C}}$ respectively. With the growth of $\mathrm{Z}_{\mathrm{C}(1)}$ the economic values of the $\mathrm{M}_{\mathrm{C}}$ parameters decrease significantly [27-32].

The economic values of the cross-sections of the head sections of the $10 \mathrm{kV} \mathrm{CL}\left(\mathrm{F}_{\mathrm{H}, \mathrm{i}}\right)$ are most sensitive to changes in the generalized constants $Z_{i(1)}, Z_{i(2)}$ and the least to a change in the constants $\mathrm{Z}_{\mathrm{i}(3)}$ and $\mathrm{Z}_{\mathrm{i}(4)}$, that is, the economic value parameter $\mathrm{F}_{\mathrm{H}, \mathrm{i}}$ is mainly determined by the cost characteristics of cable lines (Fig. 2b).

As can be seen from Fig.2a, the economic value of the number of used cross-sections of $10 \mathrm{kV}$ cables $\left(N_{F, i}\right)$ is most sensitive to changes in the generalized constants $\mathrm{Z}_{\mathrm{i}(1)}$ and $\mathrm{Z}_{\mathrm{i}(2)}$, determined by the cost characteristics of $10 \mathrm{kV}$ cable lines. For example, when the coefficients $Z_{i(1)}$ change within $0.97 \div 1.03$, the economic value of the $N_{F, i}$ parameter changes only within $0.98 \div 1.05$. Therefore, the possible range of variation of the parameter $N_{F, i}$ lies within the permissible limits with a wide change in the initial data (generalized coefficients). The influence of other generalized coefficients $\left(\mathrm{Z}_{\mathrm{i}(3)}\right.$ and $\left.\mathrm{Z}_{\mathrm{i}(4)}\right)$ on the value of the unification parameter $N_{F, i}$ is insignificant (Fig. 2a, b, c).

Thus, the reliability of determining the economic value of the parameter $M_{i}$ depends to the greatest extent on the error of the constant component of the characteristic of the cost of $10 \mathrm{kV}$ cable lines, and the accuracy of determining the parameters $F_{H, i}$ and $N_{F, i}$ depends to the greatest extent on the error in determining the cost characteristics of cable lines [33-37].

\section{Conclusions}

Thus, by analyzing the characteristics of a complex technical and economic model of $10 \mathrm{kV} \mathrm{DET}$, it was found that the reliability of determining the economic value of the parameter $M_{i}$ depends to the greatest extent on the error of the constant component of the characteristic of the cost of cable lines, and the accuracy of determining the parameters $F_{2, i}$ and $N_{F, i}$ depends to the greatest extent on the error determination of the cost characteristics of cable lines $10 \mathrm{kV}$. The significant stability of the technical and economic function to the parameter of the number of cross-sections used creates a prerequisite for further unification of the crosssections of $10 \mathrm{kV}$ DET cables.

\section{References}

1. Miron Grinkrug, Gordin S. Optimization of the parameters of urban electrical networks. "LAP Lambert Academie Publishing", 2012.

2. Venikov V.A., Venikov G.V. Theory of similarity and modeling (Applied to the problems of the electric power industry). - M.: Publishing house - "Librokom", 2014. - 440p. 3. N.M. Cheremisin, V.V. Cherkashina. A criterion method for analyzing technical and economic problems in electrical networks and systems: a tutorial. - Kharkov: Fact, 2004 -- 88 p.

4. I.Rakhmonov, A.Berdishev, N.Niyozov, A.Muratov and U.Khaliknazarov. Development of a scheme for generating the predicted value of specific electricity consumption // CONMECHYDRO - 2020. IOP Conf. Series: Materials Science and Engineering. $883 \quad$ (2020) 012103. doi:10.1088/1757-899X/883/1/012103

5. F.A.Hoshimov, I.I.Bakhadirov, M.S.Kurbanbayeva, N.A.Aytbayev. Development of specific standards of energy consumption by types of produced products of the spinning product // RSES 2020. E3S Web of Conferences. 216 (2020) 01169. https://doi.org/10.1051/e3sconf/202021601169

6. F.A.Hoshimov, I.I.Bakhadirov, A.A.Alimov, M.T.Erejepov. Forecasting the electric consumption of objects using artificial neural networks // E3S Web of $\begin{array}{llll}\text { Conferences. } & 216 & (2020) & 01170 .\end{array}$ https://doi.org/10.1051/e3sconf/202021601170

7. I.U.Rakhmonov, L.Nematov, N.N.Niyozov, K.M.Reymov, T.Yuldoshev. Power consumption management from the positions of the general system theory // ICMSIT-2020. Journal of Physics: Conference Series. 1515 (2020) 022054. doi:10.1088/1742-6596/1515/2/022054

8. I.U.Rakhmonov, F.A.Hoshimov. Development of an algorithm for evaluating the dominant factors that have the greatest impact on the energy intensity of products // ENERGY-21. E3S Web of Conferences. 209 (2020) 07018. https://doi.org/10.1051/e3sconf/202020907018 
9. Usmanov E.G. Stability in a parallel resonant circuit with active load // RSES 2020. E3S Web of Conferences. 216 (2020) 01160. https://doi.org/10.1051/e3sconf/202021601160 10. Usmanov E.G., Khusanov B.M. Phase relations in resonant circuits with a wide falling section on the amplitude characteristic // RSES 2020. E3S Web of Conferences. 216 (2020) 01161. https://doi.org/10.1051/e3sconf/202021601161 11. I.U.Rakhmonov， K.M.Reymov. Statistical models of renewable energy intermittency // RSES 2020. E3S Web of $\begin{array}{llll}\text { Conferences. } & 216 & \text { (2020) } & 01167 .\end{array}$ https://doi.org/10.1051/e3sconf/202021601167

12. I.U.Rakhmonov, N.N.Kurbonov. Analysis of automated software for monitoring energy consumption and efficiency of industrial enterprises // E3S Web of Conferences. 216 (2020) 01178. https://doi.org/10.1051/e3sconf/202021601178 13.F.A.Hoshimov, I.U.Rakhmonov, N.N.Niyozov. Technology to reduce energy costs in the electric steel melting shop // ENERGY-21. E3S Web of Conferences. 209 (2020) 07017. https://doi.org/10.1051/e3sconf/202020907017 14. A.Taslimov, F.Rakhimov, L.Nematov, N.Markaev, A.Bijanov, R.Yunusov. Economic load intervals for selecting $10 \mathrm{kV}$ cable cross-sections for agricultural consumers // CONMECHYDRO - 2020. IOP Conf. Series: Materials Science and Engineering. $883 \quad$ (2020) 012102. doi:10.1088/1757-899X/883/1/012102

15. I.Bakhadirov, N.Markaev, G.Aslanova, R.Tanatarov, S.Makhmuthonov. Differentiated tariffs of electricity for the improvement of steelmaking Uzbekistan // CONMECHYDRO - 2020. IOP Conf. Series: Materials Science and Engineering. $883 \quad$ (2020) 012121. doi:10.1088/1757-899X/883/1/012121

16. K.M.Reymov, G.R.Rafikova, L.A.Nematov, Sh.Esemuratova. Existing condition and prospects of making power balance and managing load of electric consumers in uzbek power system // ENERGY-21. E3S Web of Conferences. $\quad 209 \quad 07015$. https://doi.org/10.1051/e3sconf/202020907015

17. A.D.Taslimov, F.M.Rakhimov, A.O.Norkulov, A.A.Yuldashev. Research of the optimum scale of standard sections of agricultural purpose lines // E3S Web of $\begin{array}{lll}\text { Conferences. } & 216 & \text { (2020) }\end{array}$ https://doi.org/10.1051/e3sconf/202021601158

18. A.D.Taslimov., M.V.Melikuziev, A.M.Najimova, A.A.Alimov. Economic load intervals for selection of cable sections for agricultural purpose // E3S Web of Conferences. 216 (2020)

01159.

https://doi.org/10.1051/e3sconf/202021601159

19. Olimjon Toirov, Allabergan Bekishev, Sardor Urakov and Utkir Mirkhonov E3S Web of Conferences 216, 01116 (2020), https://doi.org/10.1051/e3sconf/202021601116

20. Olimjon Toirov, Kamoliddin Alimkhodjaev, Akhror Pardaboev Analysis and ways of reducing electricity losses in the electric power systems of industrial enterprises, E3S Web of Conferences, SUSE-2021 (2021)

21. Haqberdiev A., Toshov J. Analysis of the control system of electric motors of the running gear of self-propelled mine cars used in complex mining and technological conditions // E3S Web of Conferences 216, 01135 (2020), Rudenko International Conference "Methodological problems in reliability study of large energy systems" (RSES 2020), https://doi.org/10.1051/e3sconf/202021601135
22. K.M.Reymov,

G.Turmanova,

S.Makhmuthonov, B.Uzakov. Mathematical models and algorithms of optimal load management of electrical consumers // E3S Web of Conf. 216 (2020)

01166. https://doi.org/10.1051/e3sconf/202021601166

23. A.N.Rasulov, M.R.Ruzinazarov, N.Toirova, T.Sh.Alibekova. Graphical-analytical method for constructing load characteristics // RSES 2020. E3S Web of Conferences. $216 \quad 01171$. https://doi.org/10.1051/e3sconf/202021601171

24. Yu.Bobozhonov, B.Seytmuratov, B.Fayzullaev, A.Sultonov. Study of the influence of different designs of massive rotor of asynchronous generator on their maximum power // RSES 2020. E3S Web of Conferences. 216 (2020) 01177. https://doi.org/10.1051/e3sconf/202021601177

25. Rakhmonov I U, Reymov K M and Shayumova Z M 2019 The role information in power management tasks. E3S Web Conf 139 doi:10.1051/e3sconf/201913901080

26. Rakhmonov I U, Reymov K M 2019 Mathematical Models and Algorithms of Optimal Load Management of Electricity Consumers J ENERGETIKA. Proceedings of CIS higher education institutions and power engineering association 62(6) pp 528-535 doi:10.21122/1029-7448-201962-6-528-535

27. Rakhmonov I U, Tovbaev A N, Nematov L A and Alibekova T Sh 2020 Development of forecasted values of specific norms for the issues of produced products in industrial enterprises Journal of Physics: Conference Series 1515 doi:10.1088/1742-6596/1515/2/022050

28. Rakhmonov I U, Nematov L A, Niyozov N N, Reymov K $M$ and Yuldoshev T M 2020 Power consumption management from the positions of the general system theory Journal of Physics: Conference Series 1515 doi:10.1088/1742-6596/1515/2/022054

29. E.Usmanov, A.Rasulov, M.K.Bobojanov, R.Ch.Karimov. Non-contact voltage relay for switching windings of a boost transformer (E3S Web of Conferences, 139, 01079, 2019), https://doi.org/10.1051/e3sconf/201913901079

30. Karimov R.Ch., Bobojanov M.K., Rasulov A.N., Usmanov E.G. Controlled switching circuits based on nonlinear resistive elements (E3S Web of Conferences, 139, 01039, 2019), https://doi.org/10.1051/e3sconf/201913901039 31. Mannanov U., Toshov J., Toshniyozov L. Perspective Solutions for the Design of Drilling Tools // E3S Web of Conferences 105, 03027 (2019) IVth International Innovative Mining Symposium. DOI:10.1051/e3sconf/201910503027

32. Toshov J.B. The questions of the dynamics of drilling bit on the surface of well bottom// Arch. Min. Sci. - Poland. Vol. 61 (2016), № 2, P. 279-287. DOI 10.1515/amsc-20160020

33. Toshov Zh.B. Ways towards optimization of washout components of rock cutting tools // «GORNYI ZHURNAL»/«MINING JOURNAL», Moscow, 2016, № 2, pp. 21-24. DOI: http://dx.doi.org/10.17580/gzh.

34. A.D.Taslimov, A.S.Berdishev, F.M.Rakhimov and A.A.Yuldashev. Optimal tendency of selecting cable crosssections for agricultural electrical networks // ICMSIT-2020. Journal of Physics: Conference Series. 1515 (2020) 022056. doi:10.1088/1742-6596/1515/2/022056

35. Abduraxim Berdishev, Abdurakhim Taslimov, Bakhtiyor Melikuziev and Alibi Bijanov. Reliability indicators of $10 \mathrm{kV}$ cable lines in rural areas // FORM-2020. IOP Conf. Series: 
Materials Science and Engineering. 869 (2020) 011001. doi:10.1088/1757-899X/869/1/011001

36. A.D.Taslimov. Selection of a complex of parameters of distribution electric networks with respect to technical limitations // ENERGY-21. E3S Web of Conferences. 209 (2020) 07013. https://doi.org/10.1051/e3sconf/202020907013 37. A.Taslimov, F.Rakhimov, L.Nematov, N.Markaev, A.Bijanov, R.Yunusov. Economic load intervals for selecting $10 \mathrm{kV}$ cable cross-sections for agricultural consumers // CONMECHYDRO - 2020. IOP Conf. Series: Materials Science and Engineering. $883 \quad$ (2020) 012102. doi:10.1088/1757-899X/883/1/012102 